\title{
AS RELAÇÕES INTRADISCIPLINARES E INTERDISCIPLINARES REPRESENTADAS EM TEXTOS DE MATERIAIS CURRICULARES EDUCATIVOS
}

\author{
THE INTRADISCIPLINARY AND INTERDISCIPLINARY RELATIONS REPRESENTED IN \\ TEXTS OF EDUCATIONAL CURRICULAR MATERIALS \\ LAS RELACIONES INTRADISCIPLINARIAS Y INTERDISCIPLINARIAS REPRESENTADAS \\ EN TEXTOS DE MATERIALES CURRICULARES EDUCACIONALES
}

\author{
Reinaldo Feio Lima \\ Universidade Federal do Sul e Sudeste do Pará - UNIFESSPA \\ E-mail: reinaldo.lima@unifesspa.edu.br
}

\begin{abstract}
RESUMO
Este artigo tem como objetivo identificar e descrever como as relações intradisciplinares e interdisciplinares são representadas em textos de Materiais Curriculares Educativos. Assim, foi utilizado o conceito de classificação elaborado por Bernstein para analisar essas relações que são expressas nos textos dos Materiais Curriculares Educativos. O método da pesquisa foi qualitativo, a partir da linguagem de descrição proposta por Basil Bernstein (2000), com o uso da análise documental ancorada em constructos de sua teoria. Os resultados sugerem uma classificação fraca nas relações intradisciplinares, o que significa dizer que há existência de relação entre conteúdos distintos, porém pertencentes a uma mesma disciplina, caracterizando uma prática pedagógica por conexões intradisciplinares. Verificamos a ausência dessas relações no ensino da Matemática, portanto, os textos dos Materiais Curriculares Educativos expressam um silenciamento da prática pedagógica interdisciplinar nos processos de ensino e de aprendizagem da tarefa matemática.
\end{abstract}

PALAVRAS-CHAVE: Relações. Texto. Materiais Curriculares Educativos.

\section{ABSTRACT}

This article intends to identify and describe how intradisciplinary and interdisciplinary relations are represented in texts of the Educational Curricular Materials. Thus, it was used the concept of classification prepared by Bernstein for analyzing theses relations which are expressed in the texts of the Educational Curricular Materials. The research method was qualitative based on the language of description proposed by Basil Bernstein (2000), with the use of the documental analysis anchored in models of his theory. The results suggest a weak classification in the intradisciplinary relations which means that there is the existence of relation among distinct contents, but belonging to a same discipline, characterizing a pedagogical practice through intradisciplinary connections. We verified the absence of these relations in the Mathematics learning, therefore, the texts of the Educational Curricular Materials express a silencing of the interdisciplinary pedagogical practice in the processes of learning and teaching the math task.

KEYWORDS: Relations. Text. Educational Curricular Materials.

\section{RESUMEN}

Este artículo tiene como objeto identificar y describir como las relaciones intradisciplinarias y interdisciplinarias son representadas en textos de Materiales Curriculares Educacionales. Así, fue utilizado el concepto de clasificación, elaborado por Bernstein, para analizar esas relaciones que están expresas en los textos de los Materiales Curriculares Educacionales. El método da la pesquisa fue cualitativo, a partir del lenguaje de la 
descripción propuesta por Basil Bernstein (2000), con el uso de la análisis de documentos basada en constructos de su teoría. Los resultados sugieren una clasificación frágil en las relaciones intradisciplinarias, lo que significa decir que hay existencia de relación entre contenidos distintos, pero pertenecientes a una el misma materia, caracterizando una práctica pedagógica por conexiones intradisciplinarias. Verificamos la falta de esas relaciones en la enseñanza de la Matemática, por lo tanto, los textos de los Materiales Curriculares Educacionales expresan un silenciamiento de la práctica pedagógica interdisciplinaria en los procesos de la enseñanza y el aprendizaje de la tarea matemática.

PALABRAS-CLAVE: Relaciones. Texto. Materiales Curriculares Educacionales.

\section{INTRODUÇÃO}

Este artigo tem como objetivo identificar e descrever como as relações intradisciplinares e interdisciplinares são representadas em textos de Materiais Curriculares Educativos (MCE). Entendemos texto como qualquer forma de comunicação que pode ser escrita, falada, visual e/ou espacial, produzida na relação professor-estudante-material (BERNSTEIN, 2003). Neste estudo, os textos referem-se aos elementos que compõem os Materiais Curriculares Educativos.

Usamos a expressão "Materiais Curriculares Educativos" para nos referir aos materiais que são explicitamente delineados para apoiar a aprendizagem de professores. Esclarecemos que o adjetivo "educativo" faz menção aos docentes como aprendizes. Já a palavra "aprendizagem" foi empregada no sentido de gerar possíveis mudanças na produção de textos de professores em contato com esses materiais. Em suma, essa aprendizagem pode ocorrer por meio dos elementos: tarefa matemática, registros dos estudantes, vídeos da aula, narrativas de aulas, dentre outros. Tais elementos podem sinalizar aos(às) professores(as) diversas possibilidades na prática pedagógica de como planejar, alterar, implementar e avaliar esses materiais (DAVIS et al., 2017; MCNEILL et al., 2017; REMILLARD; KIM, 2017; FUENTES; MA, 2018).

Esses elementos trazem consigo potencialidades dos MCE quanto à sua capacidade de apoiar professores ou futuros docentes na implementação de propostas de mudanças pedagógicas nas aulas (OLIVEIRA; BARBOSA, 2016). A partir desse pressuposto, estudos têm apresentado as potencialidades passíveis de existir nos materiais, de modo a fortalecer o apoio aos professores. Como exemplo, Oliveira e Barbosa (2016) indicam as seguintes potencialidades que os MCE podem trazer:

A primeira potencialidade refere-se à análise crítica dos saberes e fazeres de professores experientes. A segunda potencialidade refere-se à fonte de inspiração para mudanças pedagógicas. A terceira potencialidade refere-se à familiaridade com as estratégias dos estudantes. A quarta potencialidade refere-se ao desenvolvimento dos próprios saberes dos licenciandos (OLIVEIRA; BARBOSA, 2016, p. 120-121). 


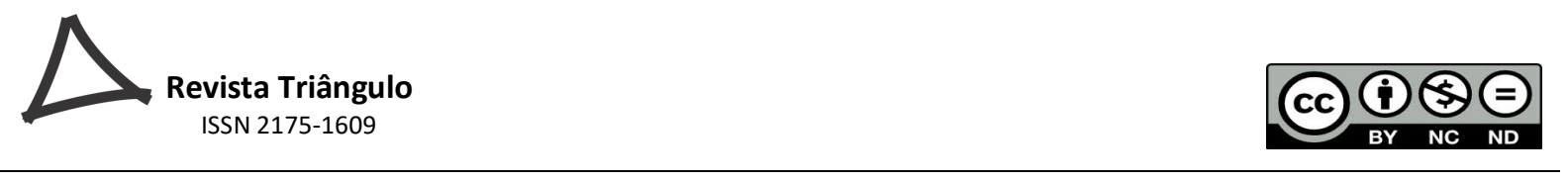

De um modo geral, essas quatro potencialidades possibilitam aos professores, em exercício e/ou em formação inicial, o verdadeiro contato com os MCE com reais chances de uso na sala de aula, como uma forma de trazer situações para discussão com os estudantes. Portanto, as potencialidades dos MCE consistem em reapresentar uma prática pedagógica, trazendo detalhes referentes ao "o que" e "como" docentes fizeram uso de algum material curricular educativo na sala de aula, ou seja, "contato com diferentes apresentações e/ou reapresentações de práticas pedagógicas da matemática escolar, o que acaba tendo um caráter formativo e sendo fonte de inspiração para o futuro professor" (OLIVEIRA; BARBOSA, 2016".

Dessa forma, são MCE produzidos para serem utilizados na prática pedagógica, a qual, segundo Bernstein (2000), é qualquer relação que ocorre entre pais e filhos, médicos e pacientes, advogados e clientes. Assim, neste artigo, compreendemos a prática pedagógica a partir das relações estabelecidas entre professor(a) e estudantes e entre estudantes no contexto da sala de aula para o processo de ensino e de aprendizagem de determinado conteúdo matemático.

Para Bernstein (2000), as relações oriundas da prática pedagógica são orientadas pela regulação dos princípios de classificação e enquadramento. Neste artigo, o foco da nossa análise será o conceito de classificação para compreender as relações discursivas (relação intradisciplinar e relação interdisciplinar). O princípio de classificação refere-se ao conteúdo da comunicação e pode apresentar variações entre forte e fraco na relação de comunicação.

Com inspiração em Prado, Oliveira e Barbosa (2016), estamos considerando os discursos intradisciplinares pela relação entre diversos conteúdos matemáticos. Sendo assim, podemos inferir que a classificação é forte quando se verifica uma separação dos conteúdos de uma mesma disciplina; e é fraca quando se aproximam os conteúdos entre os vários assuntos da disciplina. Nos discursos interdisciplinares, a relação entre diferentes disciplinas será forte quando não houver aproximação entre essas disciplinas escolares do currículo, e será considerada fraca quando essa proximidade estiver presente (BERNSTEIN, 2003).

Ademais, considerando o objetivo e os constructos teóricos que fundamentam a compreensão do objeto investigado, para a completude deste artigo, fez-se necessário apresentarmos o método e contexto da pesquisa, descritos na seção seguinte.

\section{MÉTODO E CONTEXTO}


Devido ao objetivo apresentado e às inspirações teóricas para a realização deste estudo, o presente artigo enquadra-se no método qualitativo, pois o propósito é identificar e descrever como as relações intradisciplinares e interdisciplinares são representadas em textos de Materiais Curriculares Educativos (MINAYO, 2007; GASKELL, 2010). Para realizar esta investigação, o processo de produção dos dados utilizado foi a análise documental (ALVES-MAZZOTTI, 2002).

$\mathrm{O}$ contexto da produção de dados desta pesquisa incidiu sobre três documentos. $\mathrm{O}$ primeiro é o Material Curricular Educativo (MCE1) - "Recurso Multimídia na Formação de Professores" - produzido pelo Grupo de Estudos e Pesquisas sobre Formação de Professores que Ensinam Matemática (Gepefopem). O foco de análise é uma aula desenvolvida na perspectiva do Ensino Exploratório. O caso é constituído por recortes de vídeos de diferentes etapas da aula, produções escritas de estudantes e comentários da professora antes e após a aula.

Figura 1 - Ambiente virtual do caso multimídia "Os colares"

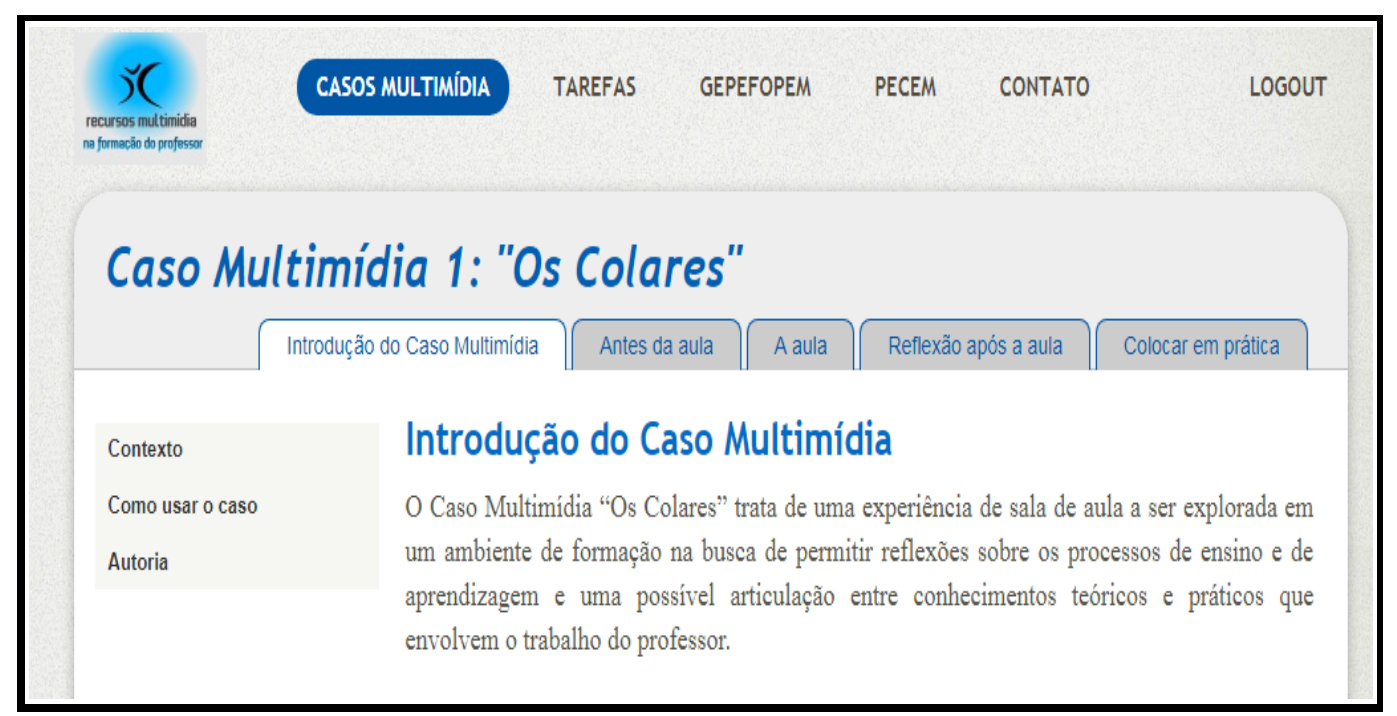

Fonte: www.rmfp.uel.br

O caso multimídia "Os colares" é composto por materiais relacionados a uma aula desenvolvida no $6^{\circ}$ ano do Ensino Fundamental com o tema "regularidades". Esse material (Figura 1) explora o tópico matemático Álgebra do Ensino Fundamental, sendo formado por quatro seções para a apresentação de diferentes aspectos da aula, especificamente: 1) Antes da aula; 2) A Aula; 3) Reflexão após a aula e 4) Colocar em prática.

$>$ Na primeira aba "Introdução do caso multimídia", são apresentadas as informações gerais do contexto em que foi desenvolvida a aula, ou seja, informações da escola, da 
professora e da turma para que o professor em formação possa conhecer um pouco do contexto no qual a aula foi desenvolvida;

$>\mathrm{Na}$ segunda aba "Antes da aula", o professor em formação (inicial ou em exercício) encontra três subseções: a tarefa, o planejamento da aula e o quadro síntese. Na subseção "a tarefa", é apresentada a tarefa "Os colares", pautada na perspectiva do Ensino Exploratório. O "Planejamento da aula" diz respeito às ações da professora (plano de aula e excertos da entrevista realizada antes de a aula ser filmada) e está estruturado em três itens: "Intenções e finalidades da aula" "Fases da aula" e "Reflexões". Por último, o quadro síntese a ser preenchido no decorrer da exploração do caso, com o intuito de capturar informações mais gerais das cinco seções;

- A terceira aba "A aula" corresponde ao desenvolvimento da aula, ou seja, às ações da professora e estudantes em torno da realização da tarefa matemática "Os colares". Tais ações estão organizadas em quatro subseções, que estão diretamente ligadas às quatro fases da aula, segundo a perspectiva do Ensino Exploratório: "Proposição e apresentação da tarefa", "Desenvolvimento da tarefa", "Discussão coletiva da tarefa" e "Sistematização";

Na quarta aba "Reflexão após a aula", propõe-se que sejam analisadas as reflexões produzidas pela regente da aula, registradas por meio da entrevista após a aula, estando estruturadas em três subseções: (1) "antes da aula", (2) "a aula" e (3) "quadro de referência ${ }^{1 "}$;

> Na quinta aba "Colocar em prática", é sugerido ao professor em formação que elabore o plano de uma aula na perspectiva do Ensino Exploratório, perpassando pelo planejamento e executando a aula. Deve também registrar em áudio e vídeo os momentos da aula e, seguidamente, fazer uma reflexão sobre como desenvolveu cada uma das etapas e quais conhecimentos matemáticos foram mobilizadas e possíveis mudanças na prática pedagógica escolar.

O segundo Material Curricular Educativo Online (MCE2) foi produzido pelo Grupo de Estudos e Pesquisas das Tecnologias da Informação e Comunicação em Educação Matemática (Gepeticem). Esse material explora conteúdos de Matemática do Ensino Fundamental II e Médio, com uso do Ambiente de Geometria Dinâmica com Tecnologia de Informação e

\footnotetext{
${ }^{1}$ Esse quadro de referência foi construído pelos membros do Gepefopem inspirados nos textos de Stein et al (2008), sendo apresentado ao professor em formação que esteja analisando o caso multimídia "Os colares", a fim de estabelecer relação com o que foi observado por ele em cada seção e anotado no quadro síntese.
} 
Comunicação. O Material Curricular Educativo, como pode ser observado a seguir, na Figura 2, desenvolvido pelo grupo (Gepeticem), é constituído por 10 MCE2, a saber: Geogebra: função do $2^{\circ}$ grau; Experimentando gráfico; Geometrizando sistemas lineares 2x2; Pontos notáveis no triângulo; Construindo gráfico da função linear no Geogebra; Será que é quadrado? Trabalhando Geometria no Sketchometry; Malha, triângulo e estrela; Bissectograma e Construindo e analisando gráficos de índice de desenvolvimento humano.

FIGURA 2 - Ambiente virtual do Material Curricular Educativo do Gepeticem.

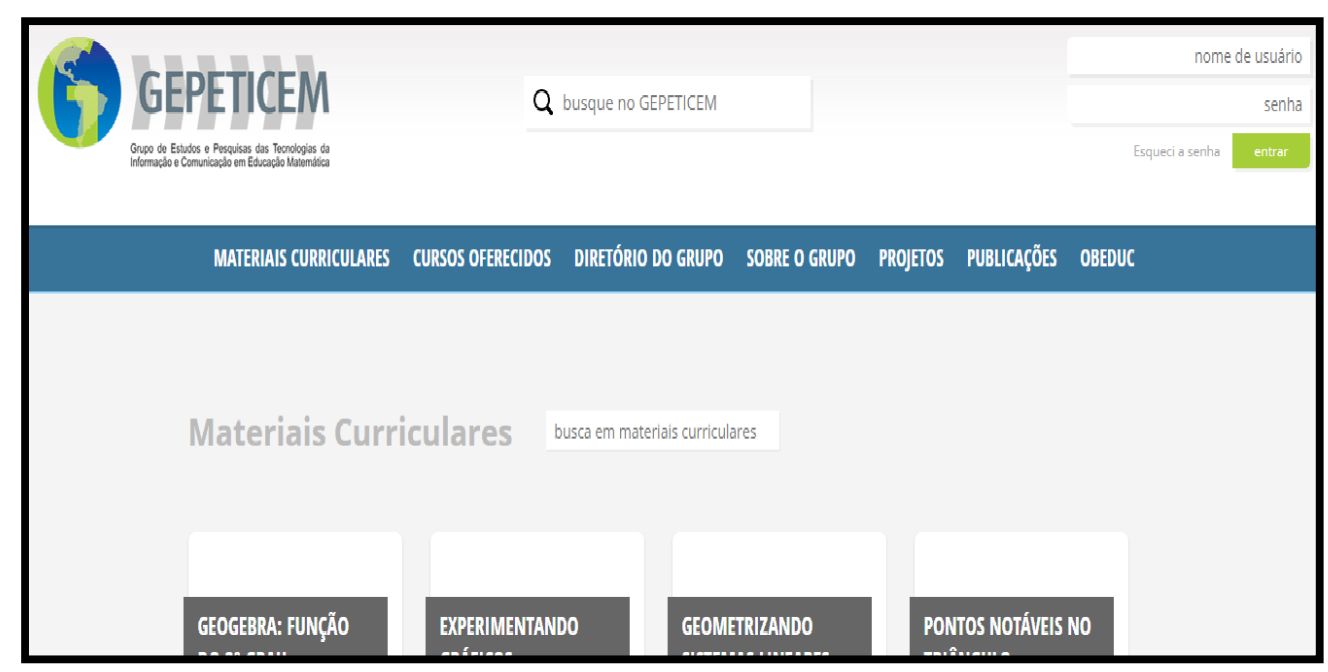

Fonte: www.gepeticem.ufrrj.br

Cada um desses MCE é composto pelos seguintes elementos:

> Apresentação: motivação e apresentação da atividade - ainda diz respeito aos conteúdos que serão desenvolvidos com o auxílio das TIC e os respectivos objetivos;

$>$ Tarefa: trata-se de uma tarefa apresentada ao estudante referente ao conteúdo matemático. Cada tarefa apresenta um tema, esclarecimento, objetivo e o material a ser utilizado, acompanhados de sugestões das etapas a serem seguidas;

> Respostas: são as estratégias (respostas) apresentadas pelos estudantes frente à tarefa; Narrativa: apresenta uma reflexão do autor sobre a parte da atividade implementada;

$>$ Vídeos: edição de fragmentos de vídeos sobre estudantes trabalhando (ou interagindo) na tarefa;

> Fórum: espaço para promover a comunicação assíncrona (comunicação em que os dados são transmitidos em qualquer ordem e cabe ao receptor interpretar essas informações e colocá-las no lugar adequado) para o aprendizado e produção de dados em tempo definido; 
Chat: espaço para promover a comunicação síncrona (comunicação que ocorre ao mesmo tempo) para o aprendizado e produção de dados;

> Comentários: espaço para que os(as) estudantes registrem suas experiências, dificuldades, postem atividades adaptadas, tirem dúvidas do material, etc.

O terceiro Material Curricular Educativo (MCE3) foi produzido pelo grupo Observatório da Educação Matemática (OEM-Bahia).

FIGURA 3 - Ambiente virtual do Material Curricular Educativo do OEM-Bahia.

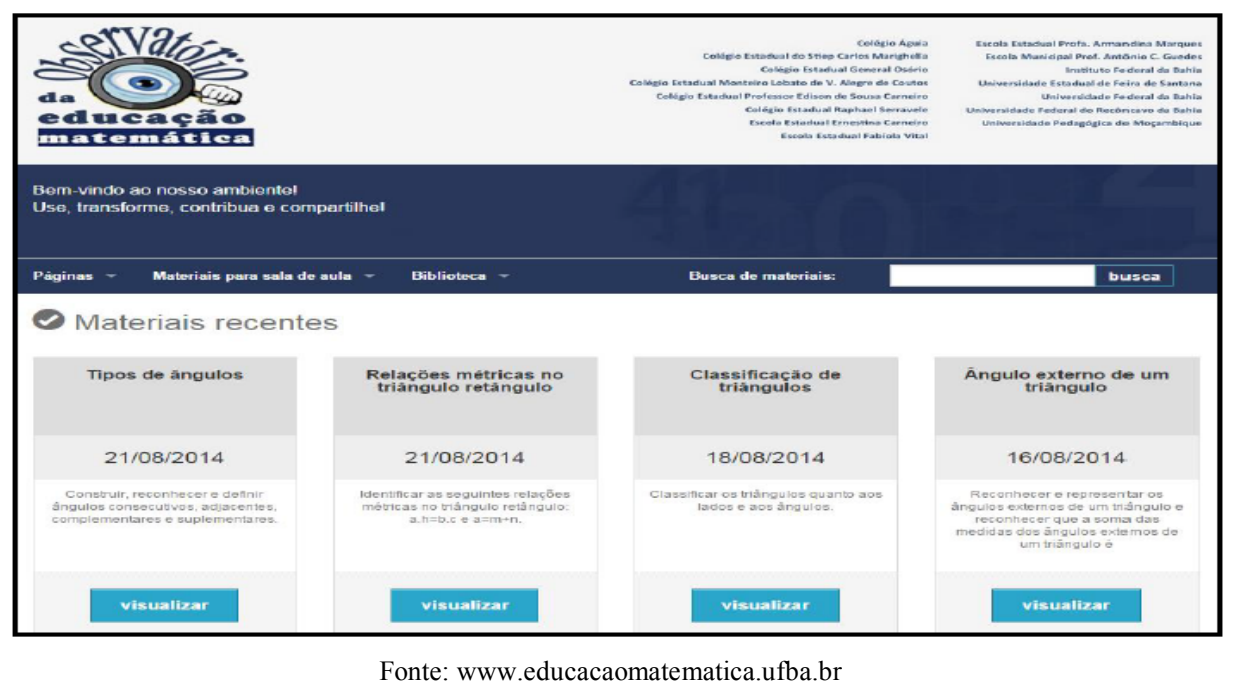

Cada MCE é composto por:

$>$ Material curricular: trata-se de uma tarefa a ser proposta ao estudante sobre o tópico da Matemática numa abordagem exploratória ou investigativa;

$>$ Material curricular comentado para o (a) professor(a): trata-se da tarefa comentada para o (a) professor(a) sob a gerência da aula, contendo orientações e sugestões sobre o conteúdo que poderia ser utilizado na aula;

> Solução do estudante: mostra as estratégias utilizadas pelos(as) estudantes na resolução da tarefa;

> Narrativa: apresenta os passos do(a) professor (a) na utilização do material na aula;

$>$ Solução do(a) professor(a): mostra uma possível solução das questões propostas no material curricular;

> Planejamento: explicita os momentos ou organização que podem desenvolver na aula, a saber: introdução, resolução da tarefa, socialização, sistematização das respostas; 
Vídeos: retrata episódios da aula considerados relevantes na sua implementação: introdução, interação professor(a)-estudantes, socialização das respostas dos estudantes e sistematização do conteúdo na resolução da tarefa pelo(a) professor(a).

Para as descrições e as análises, foi utilizado o modelo de investigação da Linguagem de Descrição de Bernstein (2000), as quais podem ser distinguidas entre linguagens de descrição internas e externas. A linguagem de descrição interna refere-se aos conceitos da teoria, neste caso, o conceito de classificação, e a linguagem de descrição externa diz respeito ao empírico, ou seja, os textos dos Materiais Curriculares Educativos. A seguir, apresentamos as descrições e as análises do estudo realizado à luz de alguns conceitos da teoria de Basil Bernstein $(2000 ; 2003)$ e da literatura.

\section{APRESENTAÇÃO E DISCUSSÃO DOS DADOS}

O Quadro 1, a seguir, nos auxilia na apresentação e discussão dos dados no que diz respeito às relações intradisciplinares e interdisciplinares.

Quadro 1 - Relações intradisciplinares e interdisciplinares representadas em textos dos MCE.

\begin{tabular}{|c|c|c|c|c|}
\hline MCE & $\begin{array}{c}\text { Título da } \\
\text { Tarefa } \\
\text { Matemática }\end{array}$ & Tarefa Matemática & $\begin{array}{c}\text { “Possíveis } \\
\text { disciplinas } \\
\text { envolvidas" }\end{array}$ & $\begin{array}{l}\text { "Possíveis } \\
\text { conteúdos } \\
\text { envolvidos" }\end{array}$ \\
\hline MCE1 & Os colares & $\begin{array}{l}\text { A Inês fez três colares, com contas pretas e brancas, } \\
\text { conforme as figuras } 1,2 \text { e } 3 \text {. } \\
\text { 1) Indique acima o número total de contas de cada } \\
\text { figura. 2) Continuando esta sequência de colares, } \\
\text { quantas contas teria, no total, o colar correspondente à } \\
\text { figura seguinte? 3) E quantas contas teria o colar } \\
\text { correspondente à figura } 8 \text { ? } \\
\text { 4) Descubra quantas contas teria, no total, o colar } \\
\text { correspondente à figura 19. 5) Existe algum colar, na } \\
\text { sequência, que tenha 55 contas? Explique, } \\
\text { detalhadamente, o seu raciocínio. 6) Descreva uma } \\
\text { regra que lhe permita determinar o número total de } \\
\text { contas de qualquer figura da sequência. }\end{array}$ & & $\begin{array}{l}\text { Número } \\
\text { Álgebra }\end{array}$ \\
\hline MCE2 & $\begin{array}{l}\text { Geometrizando } \\
\text { sistemas } \\
\text { lineares } 2 \times 2\end{array}$ & $\begin{array}{l}\text { Crie os controles deslizantes a, b e c com valor } \\
\text { mínimo -5, valor máximo } 5 \text { e incremento mude para } 1 . \\
\text { O parâmetro a representa o coeficiente de } x \text {, o } \\
\text { parâmetro b representa o coeficiente de y e o } \\
\text { parâmetro c representa o termo independente. Digite a } \\
\text { equação no campo de entrada. Clique enter e observe, } \\
\text { no campo gráfico, a reta que representa a equação. } \\
\text { Clique na ferramenta mover e escolha os } \\
\text { parâmetros a, b e c do controle. Agora, digite a } \\
\text { equação e mova os parâmetros a, b e c. }\end{array}$ & --- & $\begin{array}{l}\text { Álgebra } \\
\text { Geometria } \\
\text { Sistemas } \\
\text { Lineares }\end{array}$ \\
\hline
\end{tabular}




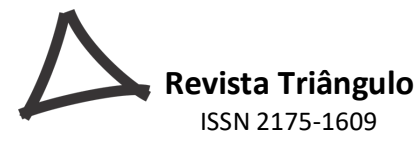

ISSN 2175-1609

\begin{tabular}{|l|l|l|l|l|}
\hline MCE3 & $\begin{array}{l}\text { Caro (a) estudante, a tarefa que vamos realizar envolve } \\
\text { angntificando } \\
\text { ângulos } \\
\text { congruentes e } \\
\text { âssetriz de um uncia de ângulos e bissetriz. Vamos começar? } \\
\text { ansino no } \\
\text { Fundamental }\end{array}$ & $\begin{array}{l}\text { 1) Construa dois ângulos no software Geogebra. No } \\
\text { primeiro ângulo, trace uma semirreta qualquer a partir } \\
\text { do seu vértice. No segundo ângulo, também a partir do } \\
\text { vértice do ângulo, trace uma "bissetriz". } \\
\text { Comente sobre o que você observou a partir dos } \\
\text { procedimentos realizados. } \\
\text { O que podemos concluir em relação à semirreta } \\
\text { traçada no primeiro ângulo e à bissetriz traçada no } \\
\text { segundo ângulo? }\end{array}$ & Aeometria \\
\hline
\end{tabular}

Fonte: Dados da pesquisa

Analisamos as relações intradisciplinares (relações entre conteúdos matemáticos) presentes em textos dos três $\mathrm{MCE}$, isto é, as variações entre os conteúdos. Assim, ao analisarmos a coluna 5, no Quadro 1, observamos que os textos dos materiais apontam possíveis modos de relacionar conteúdos matemáticos sugeridos em diferentes blocos de conteúdos conforme a Base Nacional Comum Curricular (BRASIL, 2017). Por exemplo, a tarefa matemática do MCE1, intitulada "Os colares", aponta possíveis conteúdos envolvidos na resolução da tarefa: números e operações, enquanto que a tarefa matemática do MCE2, intitulada "Geometrizando sistemas lineares $2 \times 2$ ", pode exigir na sua resolução possíveis conteúdos matemáticos: Álgebra, Geometria e Sistemas Lineares. Já a tarefa matemática do MCE3, intitulada "Identificando ângulos congruentes e bissetriz de um ângulo no Ensino Fundamental", pode envolver possíveis conteúdos matemáticos de Álgebra, Geometria e Trigonometria.

À luz da teoria de Bernstein (2000), podemos inferir que os conteúdos matemáticos encontram-se integrados por meio da tarefa matemática, ou seja, houve uma aproximação entre diferentes conteúdos da Matemática, resultando numa classificação fraca. Isso quer dizer que o enfraquecimento na classificação indica que, na prática pedagógica representada nos textos dos três Materiais Curriculares Educativos, os conteúdos são integrados por meio da tarefa matemática. Logo, a presença das relações intradisciplinares justifica-se porque o estabelecimento de relações entre os conteúdos de uma mesma disciplina favorece a constituição de uma visão integradora do conhecimento científico (GALLIAN, 2011).

Percepção semelhante a esta foi identificada por Prado, Oliveira e Barbosa (2017), ao analisarem os textos dos Materiais Curriculares Educativos sobre modelagem matemática (MCEMM). Os resultados apontam que tais materiais sugerem, por meio de seus textos, uma classificação fraca, pois os critérios de seleção e organização levaram em conta apenas a lógica 
interna da Matemática, isto é, os conteúdos encontram-se integrados por meio da tarefa matemática.

No que se refere às relações interdisciplinares (relações entre diferentes disciplinas escolares), como pode ser observado na coluna 4 do Quadro 1, as três tarefas matemáticas não apresentam articulação entre a Matemática com uma, duas ou mais diferentes áreas ou disciplinas escolares. Por exemplo, na coluna 3, as descrições das três tarefas matemáticas exemplificam a exploração do conteúdo matemático para confirmar a resposta dos estudantes. Assim, estes três Materiais Curriculares Educativos apresentam uma classificação forte, ou seja, a disciplina Matemática é sugerida de maneira isolada de outras disciplinas escolares, não um planejamento intencional que sustente a prática pedagógica interdisciplinar. Corroborando o entendimento de Lapa, Bejarano e Penido (2011), a realidade da educação brasileira é marcada, historicamente, por currículos fragmentados e desarticulados, em que as diversas disciplinas são estudadas isoladamente. É preciso discutir e vivenciar o currículo que considere a interdisciplinaridade na prática pedagógica do(a) professor(a) que ensina Matemática, pois pode auxiliar e facilitar a apropriação de novos conceitos e sua mobilização, já que, teoricamente, o(a) docente proporcionará aos estudantes uma visão mais integrada do conteúdo matemático ao desenvolver a tarefa matemática no contexto da sala de aula (SOUZA; SANTOS, 2016).

No cerne dessa discussão, a prática pedagógica interdisciplinar acontece quando, ao se explorar um tema, é necessário recorrer a conceitos e instrumentos de outra área do conhecimento ou disciplina (SANTOS; NUNES; VIANA, 2017). As relações interdisciplinares não são uma justaposição ou articulação de conteúdo, nem uma prática pedagógica que reúne mais de um professor ou disciplina. Segundo Cordiolli (2002),

\footnotetext{
No espaço escolar e acadêmico, organizados em disciplinas, a prática interdisciplinar refere-se à ação que parte de uma disciplina, mas utiliza de conceitos ou instrumentos de outras para tratar das questões previstas em seus objetivos. O professor que atua numa perspectiva interdisciplinar é aquele que domina o conteúdo de sua área e recorre a outras disciplinas para explorar plenamente os temas de que está tratando (CORDIOLLI, 2002, p. 19).
}

Sendo assim, a prática pedagógica que é reportada nos textos dos três Materiais Curriculares Educativos apresenta indícios da ausência da relação interdisciplinar, conforme apresentado na coluna 4, Quadro 1, isto é, durante o desenvolvimento da tarefa matemática ( coluna 3, Quadro 1), não recorre a outras disciplinas para explorar o tema da tarefa matemática. Inferimos, assim, que o(a) professor(a) ainda não superou as barreiras das disciplinas em 
direção a outras áreas sempre que sente esta necessidade (CORDIOLLI, 2002). Uma possível justificativa para essa constatação seria a ausência de sua previsibilidade nos textos dos MCE, resultando em um distanciamento da prática pedagógica interdisciplinar. Pelo contrário, quando prevista nos textos dos MCE, pode ser efetivada dentro dos componentes curriculares, auxiliando o(a) docente na determinação dos conteúdos curriculares e da sequência que será escolhida para as explanações na sala de aula (SANTOS; NUNES; VIANA, 2017).

Portanto, argumentamos a necessidade de estabelecer relações interdisciplinares na prática pedagógica, pois incentivará os estudantes a relacionarem conceitos da área da Matemática e disciplinas diferentes curriculares, exigindo uma relação que os levará a alcançar uma melhor compreensão do conteúdo da tarefa matemática (COIMBRA, 2000).

\section{CONSIDERAÇÕES INICIAIS}

Neste artigo, o propósito foi identificar e descrever como as relações intradisciplinares e interdisciplinares são representadas em textos de Materiais Curriculares Educativos.

Analisando e interpretando os dados levantados neste artigo, com relação aos textos dos materiais, foi possível observar uma classificação fraca nas relações intradisciplinares, o que significa dizer que há uma relação entre conteúdos distintos, porém pertencentes a uma mesma disciplina, caracterizando uma prática pedagógica por conexões intradisciplinares, ou seja, os conteúdos matemáticos são explorados de forma simultânea nos processos de ensino e de aprendizagem da tarefa matemática. Isso demonstra que uma das preocupações dos textos dos materiais é com o conteúdo curricular a ser desenvolvido na prática pedagógica do(a) professor(a) que ensina Matemática. Portanto, as conexões intradisciplinares entre os diferentes conteúdos da Matemática são capazes de facilitar a percepção dos significados dos conceitos, definições, valorizar as semelhanças e eliminar a fragmentação das ideias, contribuindo, assim, para ampliar a compreensão que permeia o entendimento dos conteúdos matemáticos. Do contrário, a ausência desta relação pode ocasionar dificuldades nos processos de ensino e de aprendizagem da Matemática (MARTINS; DIAS, 2017; LORENZATO, 2006).

Verificamos, também, que o mesmo não acontece com as relações interdisciplinares. Mesmo que seja uma necessidade dentro do princípio curricular do ensino, os textos dos Materiais Curriculares Educativos expressam um silenciamento da prática pedagógica interdisciplinar nos processos de ensino e de aprendizagem de uma disciplina de forma isolada, neste caso, da Matemática, sem estabelecer relação com o que acontece nas outras disciplinas, 
podendo esconder uma armadilha nomeada por D’Ambrósio (2011) de "gaiolas epistemológicas". Segundo o autor, trata-se de uma metáfora criada para criticar o conhecimento/conteúdo aprisionado em uma disciplina, assim como um pássaro preso em uma gaiola. Por isso, defendemos que uma "ação pedagógica centrada na interdisciplinaridade seja um incentivo para a construção de uma escola participativa e decisiva na formação social do aluno" (GONÇALVES; PIRES, 2014, p. 251).

Não concluímos, mas abrimos novas indagações e possibilidades de outras investigações a partir do tema apresentado, pois, entendemos que retomadas do tema e de práticas pedagógicas intradisciplinares e interdisciplinares representadas nos textos dos Materiais Curriculares Educativos possibilitam reverificações de futuras pesquisas. Por fim, acreditamos que as discussões geradas aqui têm o potencial para serem desenvolvidas na formação (inicial e continuada) de professores que ensinam Matemática, com possibilidades de que os usos desses materiais possam refletir sobre suas próprias práticas pedagógicas.

\section{REFERÊNCIAS}

ALVES-MAZZOTTI, A. J. O método nas ciências sociais. In: ALVES-MAZZOTTI, A. J.; GEWAMDSZNADJDER, F. O método nas ciências naturais e sociais: pesquisa quantitativa e qualitativa. São Paulo: Pioneira, 2002, p. 147-178.

BERNSTEIN, B. Class, codes and control: the structuring of pedagogic discourse. Londres: Routledge, v. 4, 2003.

BERNSTEIN, B. Pedagogy, symbolic control and identity: theory research critique. Revised Edition. London: Taylor and Francis, 2000.

BRASIL. Base Nacional Comum Curricular (BNCC). Educação é a Base. Brasília, MEC/CONSED/UNDIME, 2017. Disponível em:

http://basenacionalcomum.mec.gov.br/images/BNCC_publicacao.pdf. Acesso em: 02 dez. 2019.

CORDIOLLI, M. A relação entre disciplinas em sala de aula. Curitiba: A casa de Asterion, 2002.

COIMBRA, J de A. A. Considerações sobre a interdisciplinaridade. In: PHILLIPI JUNIOR, A.; TUCCI, C. E. M.; HOGAN, D. J.; NAVEGANTES, R. Interdisciplinaridade em Ciências Ambientais. São Paulo: Signus, 2000, p. 52-70.

D'AMBROSIO, U. A transdisciplinaridade como uma resposta à sustentabilidade. Revista Terceiro Incluído: Transdisciplinaridade e Educação Ambiental, Goiânia, v. 1, n. 1, p. 1-13, jun. 2011. 


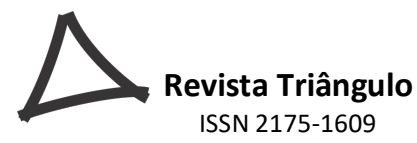

DAVIS, E. A.; PALINCSAR, A. S.; SMIRTH, P. S., ARIAS, A. M.; KADEMIAN, S. M. Educative Curriculum Materials: Uptake, Impact, and Implications for Research and Design. Educational Researcher, v. 46, n. 6, p. 293-304, 2017.

FUENTES, S. Q.; MA, J. Promoting teacher learning: a framework for evaluating the educative features of mathematics curriculum materials. Journal of Science Teacher Education, 2018, p. 351-385.

GALLIAN, C. V. A. A recontextualização e o nível de exigência conceitual do conhecimento escolar. Educaçãa e Pesquisa, v. 37, n. 4, 2011, p. 763-778.

GASKELL, G. Entrevistas individuais e grupais. In: BAUER, M.; GASKELL, G. (Org.). Pesquisa qualitativa com texto, imagem e som: um manual prático. 8. ed. Petrópolis: Vozes, 2010. p. 64-89.

GONÇALVES, H. J. L.; PIRES, C. M. C. Educação Matemática na Educação Profissional de Nível Médio: análise sobre possibilidades de abordagens interdisciplinares. Bolema - Boletim de Educação Matemática, Rio Claro, v. 28, n. 48, p. 230-254, abr. 2014.

LAPA, J. M.; BEJARANO, N. R.; PENIDO, M. C. M. Interdisciplinaridade e o ensino de ciências: uma análise da produção recente. In: ENCONTRO NACIONAL DE PESQUISA EM EDUCAÇÃO EM CIÊNCIAS, 8, 2011. Campinas. Anais eletrônicos... Campinas: ABRAPEC, 2011. Disponível em: http://www.nutes.ufrj.br/abrapec/viiienpec/resumos/R0065-1.pdf

LORENZATO, Sérgio Apparecido. Laboratório de ensino de matemática e materiais didáticos manipuláveis. In: LORENZATO, Sérgio (org.). O Laboratório de ensino de matemática na formação de professores. Campinas: Autores Associados, 2006.

MARTINS, L. P.; DIAS, M. A. Os sete aspectos considerados nas tarefas de passagem da Aritmética para a Álgebra. Amazônia - Revista de Educação em Ciências e Matemática, Belém, v. 13, n. 28, p. 90-103. Jul./dez. 2017.

MCNEILL, K. L.; GONZÁLEZ-HOWARD, M.; MARCO-BUJOSA, L.; LOPER, S.; O'DWYER, L. Na examination of how teachers' beliefs about scientific argumentation are impacted by multimedia educative curriculum materials (MECMS). [Paper to be presented at the annual meeting of the National Association for Research in Science Teaching (NARST), San Antonio, TX, 2017].

MINAYO, M. C. S. O desafio da pesquisa social. In: MINAYO, M. C. S. (Org.). Pesquisa social: teoria, método e criatividade. Petrópolis: Vozes, 2007. p. 9-29.

OLIVEIRA, A. M. P.; BARBOSA, J. C. Potencialidade de Materiais Curriculares Educativos para a Componente Curricular Prática de Ensino. Educação Matemática em Revista, n. 49B, abr. 2016.

PRADO, A. S.; OLIVEIRA, A. M.; BARBOSA, J. C. Uma análise sobre a imagem da dimensão estrutural da prática pedagógica em materiais curriculares educativos. Bolema - Boletim de Educação Matemática, Rio Claro (SP), v. 30, n. 55, p. 738-762, 2016. 
REMILLARD, J.; KIM, K. Knowledge of curriculum embedded mathematics: exploring a critical domain of teaching. Educational Studies in Mathematics, p. 1-17, 2017.

SANTOS, F. P.; NUNES, C. M. F.; VIANA, M. C. V. Currículo, interdisciplinaridade e contextualização na disciplina de Matemática. Educ. Matem. Pesq., São Paulo, v.19, n.3, pp.157-181, 2017.

SOUZA, G. M. S.; SANTOS, B. F. The influence of social context in the pedagogical practice of a chemistry teacher. In: 12th ESERA: European Science Education Research Association. Proceedings... Helsinki, 2016.

Nota dos editores:

Recomenda-se consultar, também, como referência bibliográfica, o trabalho de LIMA, R. F.; OLIVEIRA, A. M. P. Intradisciplinaridade e interdisciplinaridade representada em textos de materiais curriculares educativos. XIII Encontro Nacional de Educação Matemática. ISSN 2178-034X Cuiabá, MT. Julho de 2019. Disponível em http://docplayer.com.br/179875099-Intradisciplinaridade-e-interdisciplinaridade-representada-em-textos-demateriais-curriculares-educativos.html 